\title{
The New Broadcasting Ethos and Motivations for Interactive Technology Use in a Nigerian Radio Station
}

\author{
'WALE ONI \\ University of Salford
}

\begin{abstract}
I examine in this study what constitute the motivations/gratifications for the pervasiveness of interactive technology (mobile phone and Internet) use for participatory programming among broadcast journalists. A survey was modelled after similar studies on motivations for citizen journalism (Jack, 2009), against extant theoretical frameworks of technology adoption, including adaptive structuration and uses and gratification theories. A matrix was also constructed to pretest what constitute the motivations/gratifications for the use of interactive technology in the production of dissemination of participatory programming. Hence, broadcast journalists in a purposively selected FM radio station in southwest Nigeria were sampled. Findings showed that broadcast journalists' motivation to use interactive technology for participatory programming is geared toward information dissemination. In achieving this, broadcast journalists rely more on text-based (quasi-synchronous) new media platforms rather than a more convenient but costlier voice call channel to act the social responsibility (information dissemination and mobilization) roles. Poor telecom connectivity is a significant threat. The study, while contributing to the current discourse on the convergence of radio, also practically advances the concept of participatory communication and newsroom technology adoption beyond the theoretical and speculative dimensions.
\end{abstract}

\section{KEYWORDS}

Radio, convergence, broadcasting, interactive media, participatory programming

\section{Introduction}

One of the notable ways through which the adoption of new media has affected the media sphere is in participatory programming facilitated by the pervasive use of interactive technology. Earlier considerations of the impact of technological innovation on journalism assumed a deterministic impact of technology on the role and working practices of journalists (Spyridou et al. 2014). The discussions reflect the perception that the technological potentialities of new media will usher a 
shift that will make journalism more people centred. Technology will herald journalism into the societal function of serving the people by fostering increased accountability and transparency as well as by establishing dialogical and participatory models of communication (Kawamoto, 2003; O’Sullivan, 2005).

However, as more research took the centre stage in the past decade, a recent approach has rejected the promotion of digital utopias and favoured a well-grounded explanatory framework borne out of empirical and critical research rather than speculative and prescriptive dimension of earlier studies (Domingo, 2008). This is the social constructivist approach (Paterson, 2008; Steensen, 2011; Weiss and Domingo, 2010), which sees journalism as a social phenomenon rooted in and shaped by professional, organizational and economic factors (Fenton, 2009) and studied from extant sociological theoretical frameworks. While studies mostly in Europe and North America have reported on these trends of technology adoption in newsrooms, with the focus mainly on newspaper and online newsrooms, little or no study has been conducted in subSaharan Africa, and specifically Nigeria, on the motivations and gratifications felt by adopters of new media technologies in newsrooms, with a specific focus on the broadcast medium of radio; an acclaimed development friendly platform.

In fact, most studies on innovation and technology adoption in newsrooms have been undertaken from different disciplines and conceptualizations. In media studies, terms such as convergence and citizen or participatory journalism, but with focus on online and newspapering in the Americas, Europe and Asia are popular in the literature. Only a few instances (such as van Noort, 2007) study African news media adoption of technology or convergence. At the same time, the majority of these foreign studies emphasise the adoption of digital technology for news production and the dissemination of news through online platforms either as an aspect of the convergence phenomenon or independently through blogging and/or citizen journalism (e,g. Thurlow et al., 2004). In these studies, the focal point regarding digital technology in newsrooms revolves around the shift in media landscape as a result of the development of computers, the Internet and telecommunications. Despite this awareness, there is little or no mention of electronic media as a platform for digitalization. Only recently would a journal in Telematics and Informatics dedicate a special issue to broadcasting and more importantly radio, a vital medium in Africa. The guest editor writes this:

While convergence of media and communication technologies has been largely a characteristic of late modern society in North America and Europe, Africa has a slightly different experience. Radio remains at the very best traditional for most people who still receive it through the simple mode of traditional broadcasts. ...For example, a significant minority of radio stations and their publics have mainstreamed these technologies into their cultures and practices (Moyo, 2013b: 215)

This paper is borne out of a need to fill this important gap. It is an aspect of a wider exploratory study on interactive technology use for participatory programming by broadcast journalists in Nigeria. The wave of adoption and appropriation of computer-mediated systems by broadcast stations calls for a study on the new interactive technology use habits of broadcast journalists. Understanding the motivations to use, and gratifications derived from use, will, therefore, make 
significant contributions to knowledge at this period when the institutional culture of media/news production is undergoing a shift in paradigm. Against this backdrop, this study hopes to find answers to the following questions: What motivations and gratifications do broadcasters really seek through the adoption of digital tools for participatory programming, and what roles do usages reflect? It is also important to know the threat militating against interactive technology adoption in a developing context, and which interactive medium yields better to participatory programming.

\section{Technology acceptance and new broadcasting ethos: a theoretical and empirical review}

Acceptance and use of technology in newsrooms have always been an interesting subject of discussion among scholars in information systems, educational technology and, specifically, among scholars focusing on the sociology of newsrooms. Among the latter, there is a shifting landscape attributed to technological convergence. Not like before has technology acceptance and use been both a source of threat and blessing to media practices, radio broadcasting specifically. The internet and mobile phones are changing the face of broadcasting, taking away the power to break news which was well thought useful during disasters and coups d'états and replacing it with interactivity which makes the once passive audience to be active contributors in newsroom tasks. Their adoption and/or appropriation across the three tiers of broadcasting (private, public and community) is transforming broadcasting and thus making it at least in principle more accessible through mobility and multiplatform deliveries. For one, the geographical limitation of the FM band has been circumvented through webcasting and mobile streaming, while feedback comes through the appropriation of synchronous and quasisynchronous social media platforms. Radio is now a virtual space, network space, mobile space, while at the same time remaining a physical space when conceptualized in its studio format where citizens can participate in public debate (Moyo, 2013b: 214). These situations have impacted on the institutional practices and culture especially in the production, dissemination and eventual consumption of broadcast content. Digital technologies like the Internet and mobile phones have arguably multiplied and pluralized radio spaces (Moyo, 2013b), with promises of democratizing and increased participation.

Given this development, media scholars have developed interests in the new confluence and come out with divergent critiques along the deterministic and social constructivist dimensions. The associated problem with the deterministic and social constructivist schools of thought is that they obviously lack sophistication in grappling with the complex question of the dialectical relationship between technology, agency and structure (Moyo, 2013a: 211). A meaningful critique of the emerging digital cultures and practices must, therefore, always be grounded on the social, political, and economic contexts that acknowledge the social shaping of the new technologies used by media practitioners, with a new look at what is termed "critical theory of convergence" (Moyo, 2013a: 212). Though sharing its background in constructivist approach, the dimension remains critical as it perceives the questions of ideology and hegemony as tightly interwoven with new media and their platforms that are increasingly part of traditional broadcasting through convergence. 
Recently, scholars have attempted this purview focusing on Actor-network theory rather than through the extant theories of technology adoption and their various extensions. However, a number of studies have gone into understanding individual and organizational processes of technology adoption, including motivations for use, attitude to, and behavioural changes after, acceptance (Sun and Bhattacherjee, 2014). The studies were not just in response to the wide availability of technology in recent times, as it has also been established in the literature that the ubiquity of technology sums up to nothing other than its widespread acceptance and uses. Hence, contributions to "routinely explain over 40 percent of the variance in individual intention to use technology" (e.g. Davis et al. 1989; Taylor and Todd 1995; Venkatesh et al. 2003) have so far been made. An in-depth review of the extant models of technology acceptance, such as the Technology Acceptance Model (TAM) (Davis 1986), Motivational Model (MM) and Diffusion of Innovation Theory (DIT) (Rogers 1995), as well as how they have contributed to studies on the sociology of newswork and the more recent studies on convergence in newsrooms, have been established. The recent focus is the extended models of the unified theory of acceptance and use of technology (UTAUT) to further understand cultural, economic, and infrastructural variables that affect technology adoption in different organizational settings (Nistor et al. 2014; Mico, et al. 2014; Sun and Bachlerjee, 2014).

While both TAM and DIT have been drawn upon by scholars of sociology of newswork under rubrics such as newsroom technology adoption and/or convergence (Forte Duhe, 2004; Greenwood and Reinardy, 2011; Garrison, 2001), various other research, on newsroom technology adoption with a focus on convergence phenomenon, have reported divergent views on changing practices in newswork, and attitudinal change or perceptions of newsworkers on technology adoption (Singer, 2004). Hence, convergence and adoption of technology are integral aspects of innovation in newsrooms to which the scholars have fruitfully used DIT (Garrison, 2001; Singer, 2004). Other research projects have proposed approaches based on the social construction of technology (Boczkwoski, 2004; Cottle and Ashton, 1999), with different models trying to typify and characterize the convergence process in terms of the degree of integration of technology and journalistic practices, attitude and roles (Gordon, 2003; Dailey et al, 2005; Singer, 2004, 2006; Dupagne and Garrison, 2006; Garcial Aviles et al. 2009; Mico, et al. 2014). Their modelling efforts revealed the vast diversity of solutions that different media companies adopted to address the same innovation, as the concept remains emerging and 'a moving target for scholars' (Infotendencies Group, 2012; Quandt and Singer, 2009). The other theoretical frameworks that equally speak to studies in line with the direction of this study are briefly mentioned in the next section.

\section{Uses and gratification theory and adaptive structuration theory}

Uses and gratification theory (U\&GT) provides a theoretical framework that complements the limitations of TAM (Park, Lee and Cheong, 2007). By focusing on the motivation explained as 'a general disposition that influences the actions people take to fulfil a need or want' (Rubin, 1993) and as a factor that accounts for their selective choice and subjective interpretation of media messages (Park et al. 2007), the approach prioritizes motivations as 'driven by felt needs and individual differences' (Rosengren, 1974), which is equally pivotal in increasing people's 
behavioural intention and actual use of media technology (Park et al. 2007). U\&GT is therefore a popular approach that has been adopted in media studies (see Oni, 2013; Park et al. 2007).

DeSanctis and Poole (1994) conducted much of the early theoretical work regarding appropriation of new information communication technologies. They propose the use of adaptive structuration theory (AST) as a method for examining process change resulting from the use of advanced information communication technologies (ICTs) (see Carroll et al. 2002; Bar Pisani and Weber, 2007; Oni 2013). AST stipulates that change can be examined by focusing on the structures that are created inherent to the technology and the structures that then result from human interaction with the technology. Thus, as defined by DeSanctis and Poole, "appropriation of technology" is an ongoing practice whereby people interact with technology and then actively select structures of use from a larger set of possibilities (Carroll et al. 2002; Bar, Pisani and Weber, 2007). By this definition, appropriation occurs at the intersection of technical design and social structures. As a view of appropriation this treats the relationship between production of technology and use in action as a production of socio-technical systems (Hiltz and Johnson, 1990). Some of the notable studies in this regard are CheNeau-Loquay (2000) and Horst (2006).

\section{Method}

This research was conducted as a pre-test to a study exploring technology adoption for participatory programming in Nigeria's broadcast sector. This aspect seeks to determine the motivations for the adoption of interactive technology being used for ubiquitous participatory programming focusing on a radio station. In order to gain insight into this perspective, a survey design was employed. The survey research method remains the most empirically appropriate means of eliciting information relating to humans' knowledge, attitude and perception. Thus a conventional survey using a questionnaire as an instrument for data gathering was found to be very adequate for the size of the population. Thus, the subjects for this study were the radio presenters/producers of participatory programmes in the station. The population ( $\mathrm{N} 17$ ), comprise relatively younger staffers with mix gender ratio $\mathrm{m} 5$ : f12. The sampling technique and rationale behind this radio station is more of purposive sampling than convenience since the researcher is resident in this city.

The station which broadcast on FM band 105.5 is adjudged as one of the most listened to in southwest Nigeria with a huge listenership and social media fan followership across major social media platforms. Its major audience base comprises residents of Nigeria's most populous city of Ibadan. However, through its webcasting of programming (syndication) web/live-streaming technology listenership has increased beyond the geographic bounds of Ibadan, Nigeria. Apart from this, the station is a leading force among the fifty-six private radio stations operating in south-west Nigeria, which is actively engaging in the broad concept of convergence and/or participatory programming. A significant percentage of the programmes being aired are participatory-driven through mobile telephoning, social network sites and an interactive web-site for live streaming available at www.radio.org.ng/. There is an observed intention of democratizing its listening public by engaging them in the process of programme content production, even when no reward is promised. This claim is further affirmed by the radio station's over 70, 000 fan followership on Facebook ${ }^{\mathrm{TM}}$. 
For data gathering, a structured questionnaire was developed based on insights from Jack's (2009) matrix of motivation and an informal interview with the station's Director of Programme. As part of the procedure for data collection, a preliminary observation of the radio station was carried out. The radio station was routinely listened to for two consecutive quarters JanuaryMarch 2011 and April-June 2011. During this period, programmes with audience participation were identified and followed. Through this procedure the researcher was able to identify the presenters, the programme types, language of presentation, time of presentation and the platforms for audience participation. This informal observation assisted a great deal in constructing questionnaire items used in eliciting information from the subjects. A 3-part 27-item questionnaire was developed to assess the demography of broadcasters in the Station as well as to determine the motivation/gratification for their adoption of interactive technology for programme presentation. With the assistance of one of the presenters, questionnaires were administered to presenters and programme directors and they were retrieved just after completion.

\section{Findings}

\section{Variable Measurement}

\section{Motivations for Participatory Programming}

First, the study administered the questionnaire to the programme presenters on Splash FM 105.5 seeking to rate their gratifications and/or motivations for participatory programming. Drawing upon Jack's (2009) categorization of motivations for engaging in citizen journalism, a 27-item questionnaire was constructed and used to ask respondents to indicate their level of agreement, ranging from (0) undecided, (1) strongly disagree to (5) strongly agree. ${ }^{1}$

\section{Threats/Challenges to Adoption of Mobile phone's 2 channels and other New Media for}

\section{Participatory programming}

The second aspect of the study is in two parts: Part $A$ focuses on an assessment of the relevance of audience-participants' contribution through the associated 5 media of mobile phones (the 2 channels), Facebook, Twitter and RSS feedback/comment on the Station's website. Thus, presenters were asked to rate where contributions are most relevant to their programmes, using a 4-point scale starting from (0) not relevant to (3) very relevant. Part B seeks to assess what constitute as threats and challenges to the adoption of participatory programming, especially during the April 2011 elections. Eleven (11) statements, borne out of observations from previous studies (Banda, 2010) on citizen journalism were used to rank, from (0) Not Important to 3 (Very Important $)^{2}$, what presenters consider as threats and/or challenges to participatory programming.

\footnotetext{
${ }^{1}$ Jack's (2009) categorization of gratifications for citizen journalism: (1) Personal Gain (2) Individual Growth (3) Societal Interaction (4) Information Dissemination and (5) Collective Change. The questionnaire statements were drawn to specifically focus on motivation for participatory programming through the 5 media of mobile phones (text and voice calls), social network sites of Facebook and Twitter and, lastly, RSS feedback comment on the radio station's website.

${ }^{2}$ See APPENDIX for the questionnaire items.
} 
Radio and Participatory Programming as Election Indices

The third and the last aspect of this study focuses on interactive technology use for participatory programming as a contributing factor to polling results, judging from broadcasters' experience and perception of audience contributions to some of the special interactive programmes aired during the April, 2011 elections. Two (2) statements were used to rate respondents' level of agreement, following the Likert scale: (0) undecided, (1) strongly disagree to (5) strongly agree ${ }^{3}$.

\section{Data analysis}

Considering the small size of the sample population, being a pilot study, descriptive statistics were employed in this study. The univariate nature of the study further lends credence to the appropriateness of this approach to numeric data analysis. For the first research question, frequencies were calculated (using SPSS v.15 for Windows) for all categories representing gratifications for radio presenters' adoption of participatory programming as part of their programming against a 27-statement questionnaire. The percentage distribution and mean value for each of the categorized motivations were identified, sorted and summed to arrive at cumulative mean values for each of the block of gratifications against the motivations' statements. The results were used to predict what the radio presenters considered most as their motivations and/or gratification for the inclusion of participatory programming in their programme presentations.

Following the same analytical procedure, the percentage frequencies and mean values were derived from the 11 statements seeking to elicit information from the respondents (i.e. radio programme presenters) on $\mathbf{A}$ : what constitute threats and challenges in the course of adopting participatory programming, especially in view of the April 2011 elections in Nigeria, were sorted to determine the statement with the highest distributions; and $\mathbf{B}$ : the interactive media technology most relevant to participatory programming among the 2 channels of mobile phones, Twitter, Facebook and RSS feedback/comments on the Radio Station's website. This, of course, would mean what the radio presenters conclude to be the most significant threat/challenges to participatory programming and the most relevant technological platform for audience participation in radio programming.

\section{Results}

\section{Respondents Profile}

Respondents are radio presenters of Splash FM 105.5 in Ibadan, Nigeria. The total number (N) is seventeen (17) consisting of 5 male and 12 female presenters within the age bracket 21-40. Three of the presenters are dedicated Yoruba language presenters, while others present their programmes mainly in the English language. Other minor varieties of the English language include Nigerian and Jamaican Pidgin English.

\section{Motivations for Adopting Participatory Programming}

\footnotetext{
${ }^{3}$ See APPENDIX for the questionnaire items.
} 
The first research question asked the motivations for adopting participatory programming in radio programme presentation. Drawing on the reviewed typologies in a related study using the uses and gratifications approach, there was a pattern of five gratifications; namely, personal gain, individual growth, societal interaction, information dissemination and collective change.

To gain insight into motivations for participatory programming, statements were constructed to assess the most significant gratification for adopting participatory programming by programme presenters and producers (see Appendix). Overwhelmingly, the items located in the category of gratification for information dissemination showed to be the most important motivations for engaging audiences in participatory programming. The statement: "to inform others about news events", had its mean at 3.88 on the motivations spectrum. On the other side, the least important motivation for the respondents was to "mobilize citizens for support or protest" at a mean of 2.06 on the motivations spectrum. This perhaps indicates knowledge of the ethical responsibility in Nigerian broadcasting as provided in the National Broadcasting Commission's code of conduct (NBC Code, 2010: Section 0.3.1. paragraph 5, pg. 7). This also fairly attests to the proposition that the role of social media in social change depends not on technological merits (e.g. access to the hardware or software of new media per se), but on the attitude, interest and skills of those who use media as a means for social change (Lemish and Caringer, 2012).

In addition, respondents also indicated a high level of importance to motivations such as "to cocreate and share knowledge with audience participants", while $88.2 \%$ also agreed they use participatory programming "to know participants' first-hand experience of events about/around them"; all as part of the gratification for information dissemination.

Another interesting aspect of motivations for respondents' use of participatory programming is in the gratification for societal interaction, with an average cumulative mean score of 3.37. In the spectrum of motivations regarding societal interaction, respondents placed 3.59 on mean value for "to take part in an interactive community", while 64.7\% (3.35) placed their motivation on "to take a role in a community of new participatory programming". Thus, the interactive technologies being used for participatory programming have opened a new platform in broadcasting, where "appropriation moves" are made (Bar Pisani and Weber, 2007) as a novel approach to the "information dissemination" responsibility of media personnel with potential for engendering social change.

Furthermore, respondents claimed their "individual growth" is next to societal interaction in their order of gratification for engaging interactive technologies for participatory programming (mean 3.32). A number of the respondents placed their motivation on "to have sense of responsibility", with 3.71 mean. Next in the spectrum of motivations along individual growth of the broadcasters was "to develop an identity", with mean 3.59. However, the majority of the respondents, representing 64.7\% (3.53), placed their motivation on the "display of passion for broadcasting through participatory programming." Therefore, apart from the information dissemination and its inclination to the social responsibility role of broadcaster, the interactivity of new media equally offers to broadcasters a personal developmental platform; putting "sense of responsibility" first before "personal identity". 
It is equally interesting to know that the majority of the broadcast respondents considered "personal gain" as gratification for audience engagement. In line with this, 3.59 (64.7\%) claimed they do personally look forward to hearing/reading certain participants' contributions. A remarkable proportion (52.9\%) of the respondents also placed their motivation on "to watch and gauge audience reactions to their programmes" (3.35). However, with a 2.82 mean, "collective change" ranks as the lowest drive to participatory programming. In the spectrum of motivations, some 3.24 (representing $76.5 \%$ ) of the respondents admitted using interactivity "to set an agenda about a particular issue". Also in the block of collective change, with a mean of 3.18 , respondents show their motivation for "to reject the ordinary and offer alternative ideas to society". While it seems respondents, to some level, have grappled with participatory programming as a concept for collective change, motivations along this direction are not too impressive if compared to what obtains under information dissemination. It is important to note that motivations in this segment follow directly from Jack's (2009) typologies; however, their outcomes are different.

\section{Threats/Challenges to adoption of participatory programming}

Respondents were to rate what they consider as threats and challenges to participatory programming along a 4-point scale of importance: (0) not important to (3) very important. And an 11-item questionnaire, containing statements of perceived threats/challenges as reflected in Banda's (2010) exploration of citizen journalism in Africa, was analysed.

Overwhelmingly, respondents representing 76.5\% (mean 2.53), considered poor mobile phone networks and connectivity problems, especially during radio programme presentations, as very important threat/challenges to participatory programming, with 58.8 percent representation. Inadequate electricity supply followed with mean 2.53. However, with percentage representation of $41.2 \%$, electricity as a threat ranked among the likes of perceived low literacy level of the public (41.2\%) and "political" threat (41.2\%). The perception of insufficient audience access to enabling ICTs (such as Blackberry, I-pads, Modems, Laptops, Internet-phones, etc.) was also convincingly considered as a threat to effective audience engagement or participatory programming. 47.1 percent of the respondents indicated perceived audience's poor understanding of radio programme motif or theme as a very important threat, while $41.2 \%$ claim broadcasting ethics is "somewhat" a threat to participatory programming. Interestingly, the perceived low income status of the audience (public) was also considered "somewhat important" as a threat, with $64.7 \%$ representation and mean value of 1.76 .

It is interesting, however, to know that broadcasters" "perceived low income status of the public" (11.8\%), "ethno-religious sentiments" and "party politics" do not significantly constitute threats to participatory programming in a highly polarized state in Southwest Nigeria. Broadcasters seem not to consider low income status, with mean score of 1.76 , "very important" as a threat to using technology for participatory programming.

Another aspect of this study seeks to determine from the respondents which technological platform yields itself the most to participatory programming, especially in a developing economy exemplified in a state in Nigeria. The degree of relevance of the enabling interactive media of the mobile phones and social media networks were rated along a 4-point scale measuring relevance, with (3) very relevant to (0) not relevant. 


\section{Table 1}

Matrix of threats and challenges to participatory programming

\begin{tabular}{|l|l|l|l|l|l|l|l|}
\hline \multirow{2}{*}{ Threats/Challenges } & \multicolumn{2}{|c|}{ (3) very important - (0) not important } & Mean & S.D. & Total \\
\cline { 2 - 7 } & 3 & 2 & 1 & 0 & 2.24 & 1.091 & $17(100)$ \\
\hline $\begin{array}{l}\text { Internet connectivity during } \\
\text { presentation. }\end{array}$ & $10(58.8)$ & $3(17.6)$ & $2(11.8)$ & $2(11.8)$ & 2.24 \\
\hline $\begin{array}{l}\text { Mobile phone network and } \\
\text { connectivity during } \\
\text { presentations }\end{array}$ & $13(76.5)$ & $2(11.8)$ & $0(0)$ & $2(11.8)$ & 2.53 & 1.007 & $17(100)$ \\
\hline $\begin{array}{l}\text { Electricity supply in the } \\
\text { neighbourhoods of audience- } \\
\text { participants. }\end{array}$ & $7(41.2)$ & $8(47.1)$ & $0(0)$ & $2(11.8)$ & 2.18 & .951 & $17(100)$ \\
\hline $\begin{array}{l}\text { Insufficient access to } \\
\text { enabling ICTs such as } \\
\text { Blackberry, I-pads, Modems } \\
\text { Laptops, Internet-phones, } \\
\text { etc. by the audience- } \\
\text { participants. }\end{array}$ & $4(23.5)$ & $7(41.2)$ & $2(11.8)$ & $4(23.5)$ & 1.65 & 1.115 & $17(100)$ \\
\hline $\begin{array}{l}\text { Low literacy level of the } \\
\text { public }\end{array}$ & $7(41.2)$ & $5(29.4)$ & $2(11.8)$ & $3(17.6)$ & 1.94 & 1.144 & $17(100)$ \\
\hline $\begin{array}{l}\text { Low income status of the } \\
\text { public }\end{array}$ & $2(11.8)$ & $11(64.7)$ & $2(11.8)$ & $2(11.8)$ & 1.76 & .831 & $17(100)$ \\
\hline $\begin{array}{l}\text { Religion/Ethnicity and Party } \\
\text { politics }\end{array}$ & $5(29.4)$ & $8(47.1)$ & $2(11.8)$ & $2(11.8)$ & 1.94 & .966 & $17(100)$ \\
\hline $\begin{array}{l}\text { Poor understanding of radio } \\
\text { programme motif/theme }\end{array}$ & $8(47.1)$ & $4(23.5)$ & $3(17.6)$ & $2(11.8)$ & 2.06 & 1.088 & $17(100)$ \\
\hline $\begin{array}{l}\text { Irrelevant contributions from } \\
\text { audience-participants }\end{array}$ & $3(17.6)$ & $4(23.5)$ & $4(23.5)$ & $6(35.3)$ & 1.24 & 1.147 & $17(100)$ \\
\hline Political threats & $7(41.2)$ & $4(23.5)$ & $4(23.5)$ & $2(11.8)$ & 1.94 & 1.088 & $17(100)$ \\
\hline Broadcasting ethics & $6(35.3)$ & $7(41.2)$ & $4(23.5)$ & $0(0)$ & 1.88 & 1.166 & $17(100)$ \\
\hline
\end{tabular}

Overwhelmingly, respondents $(88.2 \%)$ indicated that mobile phones' short message service (SMS) was the most enabling platform for participatory programming (mean 2.88). Interestingly, next to this highly significant value is the use of the social media network of Facebook (mean 2.76), which $76.5 \%$ of the respondents claimed was "very relevant" to participatory programming. On the contrary, one would have thought the voice call which, of course, is the easiest to integrate into the content of radio programming - being audio-based - would receive a majority vote from the respondents. However, with $76.5 \%$ representation and mean of 2.65 , it only ranked after the text-based platforms of Facebook and SMS as a very relevant technological platform for participatory programming. A significant percentage of the respondents $(52.9 \%)$ also saw the social media network of Twitter (mean 2.47) as another text-based quasisynchronous interactive medium. The respondents claimed the RSS feed on their radio station's website received the least attention for participatory programming with mean value of 2.24. 


\section{Discussion and conclusion}

The importance of the uses and gratifications approach to new media studies, especially to gain an understanding of motivations for accessing the Internet, has been stressed further in this study. The ubiquity of mobile phones, and the convergence of the interactive media of the Internet with radio, have increased the potential of radio as a medium of mass communication. This concept has been explored in this study by expanding a study which used a profile of weblog users and its typologies to assess the motivations for audience participating in radio programming. However, because of the heterogeneous nature of the radio audience, which makes identifying an appropriate sample of the large population a bigger task, the study has focused on radio presenters of participatory programmes, and examined their gratifications and motivations for the inclusion of user generated content in radio programming. Uses and gratifications research has demonstrated that different types of media may generate new types of activity and also gratify different needs (Kim and Rubin, 1997; Perse and Dunn, 1998). More importantly, the interactive nature of Internet technology is believed to create new types of gratifications, which are quite different from those of traditional media (Charney and Greenberg, 2001; Eighmey and McCord, 1998). Therefore, it is worth examining the motivations of radio presenters as they create the nexus between radio, social media technologies and mobile phones through voice calls and textbased systems of new media.

Based on the findings from the spectrum of motivations created against five different gratifications for citizen journalism - namely, personal gain, individual growth, societal interaction, information dissemination and collective change (Jack 2009) - it was found that presenters in their majority identified with information dissemination as the most important drive for participatory programming. To inform others about news and events, and to know participants' first-hand experience of events around and/or about them, are the greatest motivations.

It is remarkable to find this tallying with Jack's (2009) motivations for audience participation in citizen journalism through the blogosphere. This means that information dissemination is the most crucial aspect of media practitioners' motivation for airing participatory programmes, which has since leveraged on the existing technologies for the inclusion of user generated content in their programmes. Thus, by giving citizens the necessary platform to create, express and share information, they are assisting the media practitioners to finally get the opportunity to fulfil this motivation. This seems to have invalidated the linear model of information dissemination through the mainstream media, especially of radio. Therefore, to determine what is news is no more the traditional prerogative of the field journalists/news correspondents and editors in newsrooms; the audience are now active participants in confirming and telling the news through participatory programming.

Given that the least important motivation for the respondents was to mobilize citizens for support or protest is, perhaps, an indication of the consciousness of the radio presenters not to use the medium to incite the public, thereby leading to mass protests. It is also an indication that ethical broadcasting is being engaged by the respondents and that they are adhering strictly to the 
provision of the National Broadcasting Commission's Code (NBC Code, 2010: Section 0.3.1. paragraph 5, pg. 7).

This study also yielded important findings on what constitute threats and challenges to participatory culture in broadcasting, considering the inadequate infrastructure and unfavourable socio-economic climate in a Nigerian state. The majority of the respondents, therefore, considered mobile phones, Internet connectivity and electricity supply in the neighbourhoods of audience-participants, respectively, as the most obvious obstacles to participatory programming. The low income status may have resulted in insufficient access to the enabling technologies/gadgets, which respondents also considered as part of the challenges to participatory programming. However, the low income status of the public, ethno-religious sentiments and partisan politics, as perceived by broadcast journalists, do not significantly constitute challenges to participatory programming, at least in Nigeria. Apart from this, the study also explored which of the technological platforms is prominently appropriated for participatory programming. It was found that the short message service of the mobile phones is mostly adopted by audience participants. This further lends credence to the claim that mobile phone networks challenge participatory programming, and in order to circumvent the impedance of voice calls, audiences became "produsers" by texting (through SMS).

In Nigeria, mobile phones became the public's technology for communication in 2001, but more than two decades ago, a sizeable portion of the elitist Nigerian publics had been engaging NITEL's (Nigeria Telecommunications) highly priced land-line for participatory programming through phone-in programmes. It is obvious that mobility, recordability, synchronicity and affordability, among other new affordances of the digital media, have democratized audience participation in radio broadcasting from the very few elite (early) adopters of the 1990s to the general public of the contemporary time. Other reasons which may have made short message service (and by extension, text-based CMC, or computer mediated communication) a preferred choice over voice calls could be the cost of maintaining voice calls in Nigeria. For instance, the billing system for inter-network calls is different from that for intra-network calls, and there are no free calls within any network. Since participation in radio programmes is often at the expense of the audience-participants (zero reward), participants will naturally prefer the channel that will be most financially affordable. We may also see another reason for this in that SMS is an asynchronous, revisable and recordable CMC system. These affordances of the technology will make participatory programming easier to embark on. However, the shortcoming of SMS, apart from its limited (160-character length) writing space, which compels 'abbronymisation' (cf. Odebunmi, 1996; Shoki and Oni, 2008) is that it is only a literacy-friendly channel of mobile phone technology, offering the opportunity of contributing to a radio programme only to the urban elites.

\section{Limitations and suggestion for future research}

In the first instance, the data of this study were based on the self-selectivity of a radio station, which was the only private radio station (in 2011) and one of the four FM radio stations in Ibadan. Although purposive sampling of its programme presenters was done, this may affect the generalizability of the results to the entire country, while it is representative of the situation in 
Ibadan, Nigeria. However, since the study focuses on the radio broadcasters rather than the heterogeneous audience, it can only give insights to gratifications and motivations felt by radio broadcasters towards participatory programming.

Therefore, it was hoped that this study may contribute to a more thorough understanding of the concept and of how and why presenters engaged audiences in programming, including the political motivations for such. In addition, open-ended questions could also be an alternative for future study. Finally, as mentioned earlier, this study does not provide a clear picture of motivations from the perspectives of audience-participants. Thus, future study should examine the relationship of audience contributions to political radio programmes and the motivations for such by the media, for a more in-depth understanding of the developmental potentials of participatory programming. Of particular interest is to see how agenda-setting, priming and framing could affect audience political orientation and reinforcement of effects of audienceparticipating in radio programmes on people's attitudes and knowledge towards politics.

\section{References}

Anderson, C. W. (2011) 'Between creative and quantified audiences: Web metrics and changing patterns of newswork in local US newsrooms', Journalism, 2011 (12), 550. DOI: $10.1177 / 1464884911402451$

Balit, S. (2012) 'Communication for development in good and difficult times', Nordicom review, 33 (2012), 105-120.

Bandura, A. (1977) Social Learning Theory, Englewood Cliffs: Prentice-Hall.

Bantz, C. R. (1982) 'Exploring Uses and Gratifications: A Comparison of Reported Uses of Television and Reported Uses of Favorite Program Type', Communication Research, 9, 352-379.

Bar, F., Pisani, F., and Weber, M. (2007) 'Draft Mobile Technology Appropriation in a Distant Mirror: Baroque Infiltration, Creolization and Cannibalism', draft paper presented at: Seminario sobre Desarrollo Económico, Desarrollo Social y Comunicaciones Móviles en América Latina. Convened by Fundación Telefónica in Buenos Aires, April 20-21, 2007.

Bechmann, A. (2011) 'Closer apart? The networks of cross-media news production', in D. Domingo and C. Paterson (eds) Making Online News - Volume 2. Newsroom Ethnography in the Second Decade of Internet Journalism. New York: Peter Lang, pp. 15-30.

Benbasat, I. and Zmud, R. (2003) 'The identity crisis within the is discipline: Defining and communicating the discipline score properties', MIS Quarterly, 27 (2), 183-194. Beyond the diffusion and social shaping perspectives. The Information Society 20(4): 255-267.

Boczkowski, P. (2004) Digitizing the News: Innovation in Online Newspapers, Cambridge: The MIT Press.

Callon, M. (1987) 'Society in the making: The study of technology as a tool for sociological analysis', in W. E. Bijker, T. P. Hughes and T. Pinch (eds) The Social Construction of Technological Systems. Cambridge, MA: MIT Press, pp. 83-110.

Carroll, J., Howard, S., Vetere, F., Peck, J., Murphy, J. (2002) 'Just what do the youth of today want? Technology appropriation by young people', Proceedings of the 35 th Hawaii International Conference on System Sciences [Online]. Available at http://www.cis.unimelb.edu.au/research/groups/customers-of-the- 
future/documents/publications/Conference/2002\%20HICSS\%20Just $\% 20$ what $\% 20 \mathrm{do} \% 20$ th e\%20youth\%20of\%20today\%20want.pdf Accessed 22 December, 2014.

CheNeau-Loquay, A. (2000) 'Africa in Global Communication Networks: from Networks to Concrete Uses', Information Development, 16 (4) 219-232. Available at http://people.lis.illinois.edu/ sthomp24/infodev/2000\%20Africa\%20Global\%20Network s.pdf

Chowdhury, A. and Hambly Odame, H. (forthcoming) 'Social Media for Enhancing Innovation in Agri-food and Rural Development: Current Dynamics in Ontario, Canada', Journal of rural and community development, accepted in 2013.

Chowdhury, A. and Hambly Odame, H. (2013) 'Do Social Media Support 'Social' Change? Insights from a Communication for Social Change Perspective in Agriculture and Rural Development', in P. Ross and J. Shtern (eds) TEM2013: Proceedings of the Technology \& Emerging Media Track - Annual Conference of the Canadian Communication Association (Victoria, June 5 -7, 2013), available from http://www.tem.fl.ulaval.ca/fr/victoriaR2013/

Claisse, G., \& Rowe, F. (1987) 'The Telephone in Question: Questions on Communication', Computer Networks and ISDN Systems, 14, 207-219.

Cohen, A. A., Levy, M. R. \& Golden, K. (1988) 'Children's Uses and Gratifications of Home VCRs: Evolution or Revolution', Communication Research, 15, 772-780.

Cohen, B. C. (1963) The Press and Foreign Policy, Princeton: Princeton University Press.

Cottle, S., Ashton, M. (1999) 'From BBC Newsroom to BBC News center: On changing technology and journalist practices', Convergence, 5 (3), 22-43.

Couldry, N. (2008) 'Actor network theory and media: Do they connect and on what terms?' in A. Hepp, F. Krotz, S. Moores and C. Winter (eds) Connectivity, Networks and Flows: Conceptualizing Contemporary Communications. Mahwah: Hampton Press, pp. 93-108.

Davis, F. D., Bagozzi, R. P., \& Warshaw, P. R. (1989) 'User acceptance of computer technology: A comparison of two theoretical models', Management Science, 35 (8), 982-1003.

Dailey, L., Demo, D. and Spillman, M. (2005) 'The convergence continuum: A model for studying collaboration between media newsrooms', Atlantic Journal of Communication 13 (3), 150-168.

DeSanctis, G., \& Poole, M. (1994) 'Capturing the complexity in advanced technology use: Adaptive Structuration Theory', Organization Science, 5 (2), 121-147.

Deuze, M. (2004) 'What is Multimedia Journalism?', Journalism Studies, 5 (2), 139-152.

Deuze, M. (2005) 'What is Journalism? Professional identity and ideology of journalists reconsidered', Journalism. Theory, Practice and Criticism, 6 (4), 442-464.

Deuze, M. (2006) 'Participation, remediation, bricolage: Considering principal components of a digital culture', The information Society, 22 (2), 63-75.

Dillon, John. (1990) 'Career values as predictor of the perceived role of media', Journalism Quarterly, 67 (2): 369-376.

Dimmick, J. W., Sikand, J., \& Patterson, S. J. (1994) 'The gratifications of the household telephone: Sociability, instrumentality, and reassurance', Communication research, 21 (5), 643-663.

Domingo, D. (2008) 'Interactivity in the daily routines of online newsrooms: Dealing with an uncomfortable myth', Journal of Computer-Mediated Communication, 13 (3), 680-704.

Dupagne, M. and Garrison, B. (2006) 'The meaning and influence of convergence: A qualitative case study of newsroom work at the Tampa news center', Journalism Studies, 7 (2), 237255 . 
Fenton, N. (2009) 'Drowning or waving? New media, journalism and democracy', in N. Fenton (ed) New Media, Old News: Journalism and Democracy in the Digital Age. London: Sage.

Fish, A. (2013) 'Participatory Television: Convergence, crowdsourcing, and neoliberalism', Communication, Culture and Critique, 6 (2013), 372-395.

Forte Duhe, S., Mortimer, M. M. and Chow, S. S. (2004) 'Convergence in North American TV newsrooms: A nationwide look', Convergence, 10 (2), 81-104.

García Avilés, J. A., Meier, K., Kaltenbrunner, A., Carvajal, M., \& Kraus, D. (2009) 'Newsroom integration in Austria, Spain and Germany: Models of media convergence', Journalism Practice, 3 (3), 285-303.

Garrison, B. (2001) 'Diffusion of online information technologies in newspaper newsrooms', Journalism, 2 (2), 221-239.

Girard, B. (2003) 'Radio and the internet: mixing media to bridge the divide. The one to watch: radio, new ICTs and interactivity', Rome: United Nations Food and Agriculture Organization (FAO).

Gordon, R. (2003) 'The meanings and implications of convergence', in K. Kawamoto (ed) Digital journalism: Emerging media and the changing horizons of journalism, Oxford: Rowman \& Littlefield Publishers, pp. 57 - 74.

Greenwood, K. and Reinardy S. (2011) 'Self-trained and self-motivated: Newspaper photojournalists strive for quality during technological challenges', Visual Communication Quarterly, 18 (3), 155-166.

Available

at http://www.tandfonline.com/doi/abs/10.1080/15551393.2011.599285\#.VLoyBEesXTo

Hemmingway, E. (2008) Into the newsroom: Exploring the digital production of regional television news, London and New York: Routledge.

Hiltz, S., and Johnson, K. (1990) 'User satisfaction with computer-mediated communication systems', Management science, 36 (6), 739-764.

Horst, H. (2006) 'The Blessings and Burdens of Communication: Cell Phones in Jamaican Transnational Social Fields', Global Networks, 6 (2), 143. Available at http://www.sarpn.org.za/documents/d0003008/Africa_ecn_prospect_challenges_Feb2008 .pdf. Accessed 7 March 2008.

Hu, P. J., Chau, P. Y. K., Sheng, O. R. L. and Tam, K. Y. (1999) 'Examining the technology acceptance model using physician acceptance of telemedicine technology', Journal of Management Information Systems, 16 (2), 91-112.

Infante, D. A., Rancer, A. S., \& Womack, D. F. (1993). Building communication theory ( $2^{\text {nd }}$ ed.). Prospect Heights: Waveland Press.

Infotendencias Group (2012) 'Media convergence', in E. Siapera and A. Veglis (eds) Handbook of Global Online Journalism, Malden: Oxford and Chichester: Wiley-Blackwell, pp. 2138.

Jack, M., (2009) 'The social evolution of citizen journalism', Canadian journal of media studies, (6) 1 , pp. 95-158.

Kawamoto, K. (2003) Digital Journalism - Emerging Media and the Changing Horizons of Journalism. Lanham: Rowman and Littlefield.

Lehmann, M. (2010) 'Participatory journalism: Risks and opportunities for newspaper companies to grow with user-generated contents', Opinion Paper. Germany Detecon International $\mathrm{GmbH}$. 
Leung, L. and Wei, R. (2000) 'More than just talk on the move: uses and gratifications of the cellular phone', Journalism and Mass Media Quarterly, 77 (2), 308-320.

Lievrouw, L. (2002) 'Determination and contingency in new media development: Diffusion of innovations and social shaping of technology perspectives', in L. Lievrouw and S. Livingstone (eds) The Handbook of New Media, London: Sage, pp. 181-199.

Lin, C., Salwen, M. B., Abdulla, R. A. (2005) 'Uses and gratifications of online and offline news: new wine in an old bottle?', in M. B. Salwen, B. Garrison, P. D. Driscoll (eds), Online News and the Public, Mahwah: Lawrence Erlbaum Associates, pp. 221-236.

Mathurine, J. (2008) 'New Media and its effects on journalism and media development, including Citizen Journalism', paper delivered to African Forum for Media Development Building Capacity for Media Development Grahamstown, South Africa. Available at http://www.misa.org/downloads/afmd/Newmedia.pdf.

Micó, J. L, Masip, P. and Domingo, D. (2013) 'To wish impossible things*: Convergence as a process of diffusion of innovations in an actor-network', International Communication Gazette, 75, 118-137.

Moyo, L. (2013a) 'Introduction: Critical reflections on technological convergence on radio and the emerging digital cultures and practices', Telematics and Informatics, 30 (2013), 214222.

Moyo, L. (2013b) 'The digital turn in radio: A critique of institutional and organizational modeling of new radio practices and cultures', Telematics and Informatics, 30 (2013), 214222.

Newhagen, J. E., \& Rafaeli, S. (1996) 'Why communication researchers should study the Internet: A dialogue', Journal of Computer-Mediated Communication, 1 (4), 0-0.

Nistor, N., Lerche T., Weinberger A., Ceobanu C., and Heymann O. (2014) 'Towards the integration of culture into the unified theory of acceptance and use of technology', British Journal of Educational Technology, 45 (1), 36-55.

Odebunmi, A. (1996) 'Abbreviations and acronyms in MESTA texts', in E. Adegbija and A. Ofuya (eds), English Language and Communication Skills for MESTA Students, Ilorin: Unilorin Press.

O’Sullivan, J. (2005) 'Delivering Ireland: Journalism's search for a role online', Gazette, 67 (1), 45-68.

O’Sullivan, J., Heinonen, A. (2008) 'Old values, new media: Journalism role perception in a changing world', Journalism Practice, 2 (3), 357-371.

O'Donell, A. (2011) 'Farming Out' Agricultural advice through radio and SMS'. Available at http://newswatch.nationalgeographic.com/2011/04/26/\%E2\%80\%9CfarmingRout\%E2\%80 \%9D-agricultural-advice-through-radio-and-sms/. Accessed 17 September, 2012.

Orlikowski, W. J., \& Iacono, C. S. (2001) 'Research commentary: Desperately seeking the "IT" in IT research-A call to theorizing the IT artifact', Information systems research, 12 (2), 121-134.

Palmgreen, P. (1984) 'Uses and gratifications: A theoretical perspective', Communication Yearbook, 8, 20-55.

Palmgreen, P., Wenner, L. A., and Rosengren, K. E. (1985) 'Uses and gratifications research: The Past Ten Years' in K. E. Rosengren, L. A. Wenner, and P. Palmgreen (eds) Mass Gratifications Research: Current Perspectives, Beverly Hills: Sage, pp. 11-37.

Papacharissi, Z., and Rubin, A. M. (2000) 'Predictors of Internet Use', Journal of Broadcasting \& Electronic Media, 44 (2), 175-196. 
Park, N. (2010) 'Adoption and use of computer-based Voice over internet protocol phone service: Toward an integrated model', Journal of Communication 60, 40-72.

Park, N., Lee, K. M., and Cheong, P. H. (2007) 'University Instructors' Acceptance of Electronic Courseware: An Application of the Technology Acceptance Model', Journal of Computer-Mediated Communication, 13 (2009). Available at http://jcmc.indiana.edu/vol13/issue1/park.html. Accessed November 152007.

Quandt, T. and Singer, J. B. (2009) 'Convergence and cross-platform content production', in K. Wahl-Jorgensen and T. Hanitzsch (eds) Handbook of Journalism Studies, New York: Routledge.

Rafaeli, S. (1986) 'The Electronic Bulletin Board: A Computer-driven mass medium', Computers and the social sciences, 2, 123-136.

Rogers, E. (2003) Diffusion of Innovations, 5th ed., New York: Free Press.

Rogers, E. M., (1995) Diffusion of Innovations, 4th ed., New York: Free Press.

Rosengren, K. E. (1974) 'Uses and gratifications: A paradigm outlined', in J. G. Blumler, and E. Katz (eds) The use of mass communications: Current perspectives on gratifications research, Beverly Hills: Sage, pp. 269-289.

Rubin, A. M. (1986) 'Uses, gratifications, and media effects research', in J. Bryant and D. Zillman (eds) Perspectives on Media Effects, Hillsdale: Lawrence Erlbaum Associates, pp. 281-301.

Rubin, A. M. (1993) 'Audience, activity and media use', Communication Monographs, 60, 98105.

Rubin, A. M. (2002) 'The Uses-and-gratifications perspective of media effects', in J. Bryant, and D. Zillman (eds), Media effects: Advances in theory and research (2nd ed.), Mahwah: Lawrence Erlbaum Associates, pp. 525-548.

Rubin, A. M., and Bantz, C. R. (1987) 'Utility of videocassette recorders', in J. L. Salvaggio and $\mathrm{J}$. Bryant (eds), Media use in the information age: Emerging patterns of adoption and consumer use, Hillsdale: Lawrence Erlbaum Associates, pp. 181-195.

Rubin, R. A., Perse, E., and Barbato, C. (1988) 'Conceptualization and measurement of Interpersonal communication motives', Human Communication Research, 14 (4), 602628.

Shoki, G. O. and 'Wale, O. (2008) 'Semiotic Analysis of Computer-Mediated Communication in Selected Instant Messages of Nigerian Students', in QWERTY: Rivista italiana di tecnologia cultura e formazione (Journal of Technology, Culture and Education) 3 (1), 2147. Available at www.ckbg.org/qwerty/index.php/qwerty/article/download/34/33.

Singer, J. B. (2004) 'Strange bedfellows? The diffusion of convergence in four news organizations', Journalism Studies, 5 (1), 3-18.

Singer, J. B. (2006) 'Partnership and public service: Normative issues for journalists in converged newsrooms', Journal of Mass Media Ethics, 21 (1), 30-53.

Spyridou, L-P, Matsiola, M., Veglis, A., Kalliris, G. and Dimoulas, C. (2014) Journalism in a state of flux: journalists as agents of technology innovation and emerging 'news practices', The International Communication Gazette, 75 (1), 76-98.

Steensen, S. (2011) 'Online journalism and the promises of new technology', Journalism Studies, 12 (3), 311-327.

Sun, Y., and Bhattacherjee, A. (2014) 'Looking beyond the "IT" black box: technology effects on IT usage', Journal of Computer Information Systems, Winter 2014, 1-15. 
Taylor, S., and Todd, P. A. (1995) 'Understanding Information Technology Usage: A Test of Competing Models', Information Systems Research, 6 (4), 144-176.

Thurlow, C., Lengel, L. and Tomic, A. (2004) Computer mediated communication: Social interaction and the internet, London: Sage Publications.

van Noort, E. E. (2007) 'Newsroom convergence at the Mail and Guardian: A qualitative case study', unpublished MA Thesis, Rhodes University.

Venkatesh, V., Morris, M. G., Gordon, B. D. and Davis, F. D. (2003) 'User acceptance of information technology: Toward a unified view’, MIS Quarterly, 27 (3), 425-478.

Venkatesh, V., Thong, J. Y. L. and Xu, X. (2012) 'Consumer acceptance and use of information technology: extending the unified theory of acceptance and use of technology', MIS Quarterly, 36 (1), 157-178.

'Wale, O. (2013) 'An Exploration of Fundamental Theories, Models and Perspectives on Computer-Mediated Communication', African Nebula, 6, 43-60.

Weiss, A. S., Domingo, D. (2010) 'Communities of practice innovation processes in online newsrooms as actor-networks and communities of practice', New Media and Society, 12 (7), 1156-1171.

Williams, R. and Edge, D. (1996) 'The social shaping of technology', Research Policy, 25 (6), 865-899.

Williams, F., Dordick, H. and Jesulae, H. (1985) 'Focus Group and Questionnaire Development for Exploring Attitudes Towards Telephone Service', in F. Williams (ed) Social Research and the Telephone, Los Angeles: Herbert Dordick and Associates.

\section{'Wale Oni is a postgraduate student in the School of Arts and Media (MediaCityUK), University of Salford, Manchester}

Email: o.oni1@edu.salford.ac.uk 


\section{Appendix}

\section{Table 2}

Motivation for adopting participatory programming

\begin{tabular}{|c|c|c|c|c|c|c|c|c|}
\hline \multirow[b]{2}{*}{ Personal Gain } & \multicolumn{5}{|c|}{$\begin{array}{r}\text { Motivation } \\
\text { (4) strongly agree }-(0)\end{array}$} & \multirow[b]{2}{*}{ Mean } & \multirow[b]{2}{*}{$\mathrm{Sd}$} & \multirow[t]{2}{*}{ Total } \\
\hline & 4 & 3 & 2 & 1 & 0 & & & \\
\hline $\begin{array}{l}\text { I enjoy speaking to audience } \\
\text { and reading their content } \\
\text { (Tweet and Facebook } \\
\text { comments/postings) }\end{array}$ & $6(35.3)$ & $9(52.9)$ & $1(5.9)$ & $0(0)$ & $1(5.9)$ & 3.12 & .993 & $17(100)$ \\
\hline $\begin{array}{l}\text { To pass (air) time during radio } \\
\text { programme presentation. }\end{array}$ & $4(23.5)$ & $3(17.6)$ & $5(29.4)$ & $2(11.8)$ & $3(17.6)$ & 2.18 & 1.425 & $17(100)$ \\
\hline $\begin{array}{l}\text { To watch and gauge audience } \\
\text { reactions to my radio } \\
\text { presentations. }\end{array}$ & $9(52.9)$ & $5(29.4)$ & $3(17.6)$ & $0(0)$ & $0(0)$ & 3.35 & .786 & $17(100)$ \\
\hline $\begin{array}{l}\text { I personally look forward to } \\
\text { hearing/reading certain } \\
\text { participant's contribution. }\end{array}$ & $11(64.7)$ & $5(29.4)$ & $1(5.9)$ & $0(0)$ & $0(0)$ & 3.59 & .618 & $17(100)$ \\
\hline $\begin{array}{l}\text { To influence audience- } \\
\text { participant's attitude/behavior. }\end{array}$ & $4(23.5)$ & $\begin{array}{l}14(76.5 \\
)^{2}\end{array}$ & $0(0)$ & $0(0)$ & $0(0)$ & 3.24 & .437 & $17(100)$ \\
\hline To generate income/revenue & $7(41.2)$ & $4(23.5)$ & $2(11.8)$ & $4(23.5)$ & $0(0)$ & 2.82 & 1.237 & $17(100)$ \\
\hline $\begin{array}{lll}\begin{array}{l}\text { To compete } \\
\text { presenters }\end{array} & \text { with fellow } \\
\end{array}$ & $3(17.6)$ & $5(29.4)$ & $4(23.5)$ & $5(29.4)$ & $0(0)$ & 2.35 & 1.115 & $17(100)$ \\
\hline Individual Growth & 4 & 3 & 2 & 1 & 0 & Mean & $\mathrm{Sd}$ & Total \\
\hline $\begin{array}{l}\text { To find answers to some } \\
\text { personal issues }\end{array}$ & $6(35.3)$ & $6(35.3)$ & $3(17.6)$ & $0(0)$ & $2(11.8)$ & 2.82 & 1.286 & $17(100)$ \\
\hline $\begin{array}{l}\text { To gain status and build my } \\
\text { reputation }\end{array}$ & $4(23.5)$ & $6(35.3)$ & $7(41.2)$ & $0(0)$ & $0(0)$ & 2.82 & .809 & $17(100)$ \\
\hline I have a sense of responsibility & $14(82.4)$ & $2(11.8)$ & $0(0)$ & $1(5.9)$ & $0(0)$ & 3.71 & .772 & $17(100)$ \\
\hline To develop an identity. & $10(58.8)$ & $7(41.2)$ & $0(0)$ & $0(0)$ & $0(0)$ & 3.59 & .507 & $17(100)$ \\
\hline To display my passion. & $11(64.7)$ & $5(29.4)$ & $0(0)$ & $1(5.9)$ & $0(0)$ & 3.53 & .800 & $17(100)$ \\
\hline To articulate my own ideas. & $8(47.1)$ & $9(52.9)$ & $0(0)$ & $0(0)$ & $0(0)$ & 3.47 & .514 & $17(100)$ \\
\hline \multirow[t]{2}{*}{ Societal Interaction } & & & & & & & & \multirow[b]{2}{*}{ Total } \\
\hline & 4 & 3 & 2 & 1 & 0 & Mean & $\mathrm{Sd}$ & \\
\hline $\begin{array}{l}\text { To develop connections with } \\
\text { other people }\end{array}$ & $7(41.2)$ & $\begin{array}{l}10(58.8 \\
)^{2}\end{array}$ & $0(0)$ & $0(0)$ & $0(0)$ & 3.41 & .507 & $17(100)$ \\
\hline To debate on societal issues & $5(29.4)$ & $9(52.9)$ & $0(0)$ & $3(17.6)$ & $0(0)$ & 3.12 & .697 & $17(100)$ \\
\hline $\begin{array}{l}\text { To take a role in the } \\
\text { democratization through radio } \\
\text { programme presentation. }\end{array}$ & $10(58.8)$ & $6(35.8)$ & $0(0)$ & $0(0)$ & $1(5.9)$ & 3.41 & 1.004 & $17(100)$ \\
\hline $\begin{array}{l}\text { To take part in an interactive } \\
\text { community. }\end{array}$ & $10(58.8)$ & $7(41.2)$ & $0(0)$ & $0(0)$ & $0(0)$ & 3.59 & .507 & $17(100)$ \\
\hline $\begin{array}{l}\text { To take a role in a community } \\
\text { of new participatory journalists. }\end{array}$ & $11(64.7)$ & $6(35.3)$ & $0(0)$ & $0(0)$ & $0(0)$ & 3.35 & .493 & $17(100)$ \\
\hline Information Dissemination & & & & & & & & \\
\hline
\end{tabular}




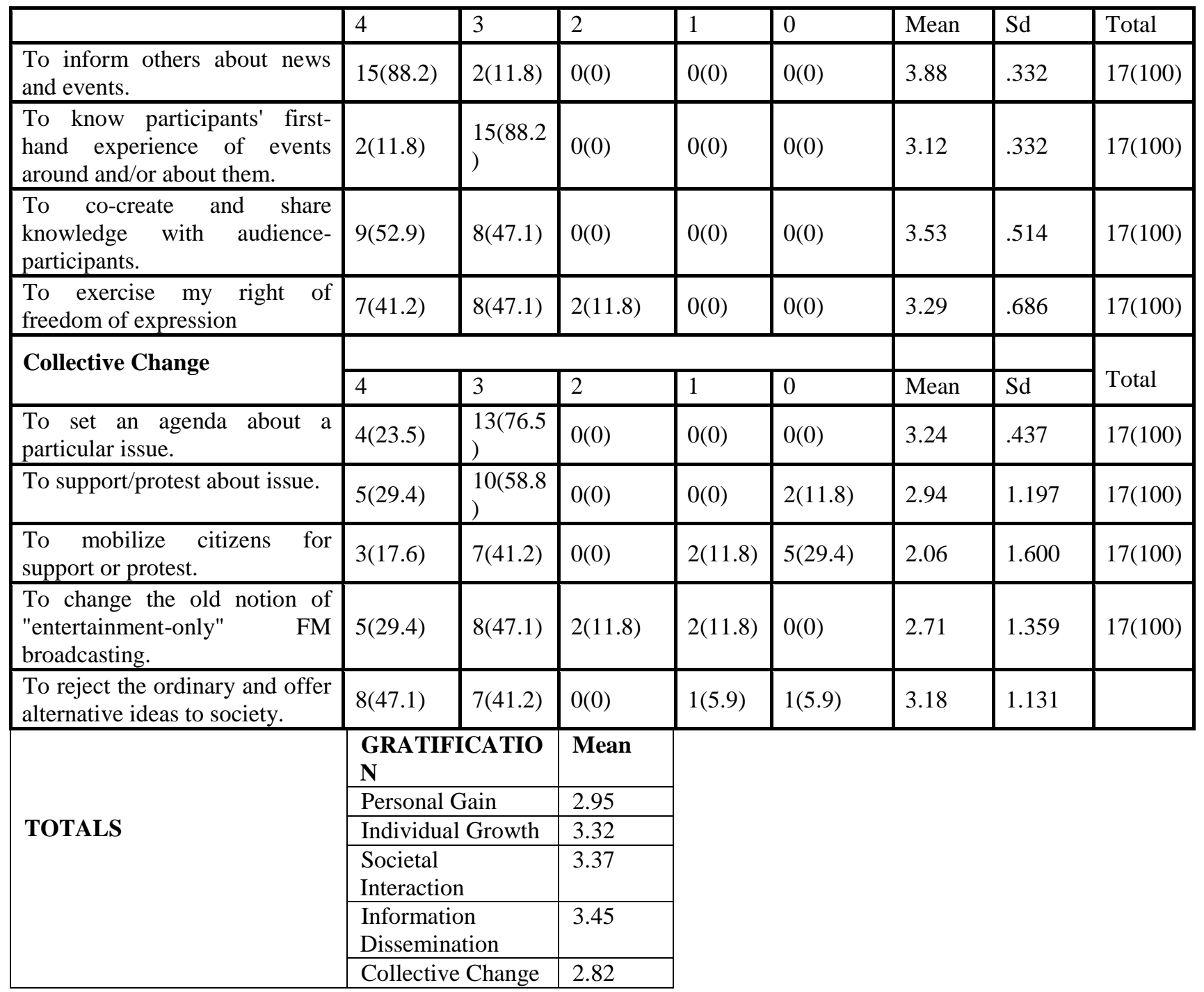

